\title{
An Empirical Analysis of Financing Constraints of Private Enterprises in China
}

\author{
Yanjun Yang ${ }^{1, a}$ \\ ${ }^{1}$ Department of Economics and Management, Party School of the Wuhan Municipal Committee of CP.C, Wuhan, China
}

\begin{abstract}
To analyze the financing problems of private enterprises in China, this paper uses the financial data of A-share listed enterprises to construct four sets of Euler investment equation models. The empirical analysis of the models indicates that Chinese enterprises are generally facing financing constraints. However, compared with the state-owned enterprises, the financing constraints of private enterprises are more serious and common. To solve the financing dilemma of private enterprises, we need to deepen the structural reform of the financial supply-side, promote the transformation and upgrading of private enterprises, improve financial infrastructure and create a favorable financing environment.
\end{abstract}

\section{Introduction}

In the past 40 years of reform and opening-up, the nonstate sector of China has been growing steadily. However, compared with state-owned enterprises, private enterprises in China are small in scale, short in development time, and face serious institutional constraints in many fields. The report "MSME Finance Gap: Assessment of Shortfalls and Opportunities in Financing Micro, Small and Medium Enterprises in Emerging Markets" issued by the World Bank in 2018 shows that the potential financing demand of small and medium-sized enterprises in China amounts to $\$ 4.4$ trillion, while the financing supply is only $\$ 2.5$ trillion. The proportion of potential financing gap is $43.18 \%$. Only $34.1 \%$ of small and micro enterprises have obtained bank loans. Some enterprises have to seek private loans to meet their investment needs. Others can only rely on their funds to develop their production.

According to the classic M-M theory proposed by F. Modigliani and M. Miller ${ }^{[1]}$, in the perfect capital market without friction, the internal and external financing of enterprises can be completely substituted. The value of enterprises is unrelated to their capital structure, and the growth of enterprises does not depend on the internal capital. However, when the capital market is not perfect, the friction of the capital market increases the financing cost of the external financing, which leads to significantly higher external financing costs than internal financing costs. The financing activities of the enterprise will be constrained by the financing cost and quantity. If it is difficult for the enterprise to raise enough funds at a lower cost, they can only be forced to give up some valuable investment opportunities. Fazzari et al (1988) defined this phenomenon as the financing constraint ${ }^{[2]}$.
At present, enterprises in China, especially small and medium-sized private enterprises are facing financing constraints.

\section{Methodology}

\subsection{The model}

To judge whether enterprises are facing financing constraints, this paper uses the Euler investment equation model. The model was first proposed by Abel (1980) and is mainly used to describe the optimal investment behavior of a company. Later, Laevel (2003), Bond and Meghir (1994) introduced the profit equation and cost adjustment function into the model ${ }^{[3]}$, and obtained the final Euler investment equation model as follows:

$\left(\frac{I}{K}\right)_{\mathrm{it}}=\beta_{o}+\beta_{1}\left(\frac{I}{K}\right)_{\mathrm{i}, \mathrm{t}-1}+\beta_{2}\left(\frac{I}{K}\right)_{\mathrm{i}, \mathrm{t}-1}^{2}+\beta_{3}\left(\frac{Y}{K}\right)_{\mathrm{i},-1-1}+\beta_{4}\left(\frac{C F}{K}\right)_{\mathrm{i},-1-1}+\xi_{i t}$ (1)

Where $I$ is the investment of the enterprise, $K$ is the capital, $Y$ is the total income, $C F$ is the cash flow, and $\xi_{\text {it }}$ is a random disturbance term. The equation shows that the investment of an enterprise is constrained by two aspects: internal capital accumulation and external financing. $\left(\frac{I}{K}\right)_{\mathrm{i}, \mathrm{t}-1},\left(\frac{I}{K}\right)_{\mathrm{i}, \mathrm{t}-1}$ and $\left(\frac{Y}{K}\right)_{\mathrm{i}, \mathrm{t}-1}$ can reflect the internal capital accumulation of an enterprise, and $\left(\frac{C F}{K}\right)_{\mathrm{i}, t-1}$ can reflect the cash flow of an enterprise.

The coefficients $\beta_{1}, \beta_{2}, \beta_{3}, \beta_{4}$ respectively reflect the sensitivity of the investment behavior of enterprises to each variable. The results of Laeven (2003) show that: when $\beta_{1}>1, \beta_{2}<-1, \beta_{3} \geq 0, \beta_{4}<0$, the investment behavior of enterprises conforms to the optimal path in theory.

aYangyanjun0221@aliyun.com 
Otherwise, the investment behavior of an enterprise is not optimal. $\beta_{4}$ reflects the investment cash flow sensitivity of enterprises, which can be used to measure the degree of financing constraints faced by enterprises. When $\beta_{4}>0$, it means that the investment of the enterprise is more sensitive to the internal cash flow, and the enterprise faces external financing constraints.

\subsection{Sample selection}

This paper takes the data of China's A-share listed companies in 2017-2018 as an empirical analysis sample. The sample size is 3711 . To ensure the validity of the data and eliminate the influence of abnormal samples on the research conclusion, this paper deals with the samples as follows:

First, we have selected manufacturing enterprises as the research samples, excluding the samples of real estate and financial enterprises. It is mainly because the capital expenditure characteristics of financial enterprises and real estate enterprises are quite different from that of the manufacturing industry. The proportion of fixed assets of these two types of enterprises is small and the specificity of assets is not strong, which can not reflect the characteristics of physical investment. Besides, these two types of enterprises account for a small proportion of China's listed companies and are not representative. Second, We have eliminated the enterprises in the state of $* \mathrm{ST}$ and ST in A-share ${ }^{[4]}$. Because the reorganization and integration of such enterprises are very common, normal production and operation cannot be sustained, and the reliability and relevance of accounting indicators are insufficient. Thirdly, we have eliminated the abnormal data and incomplete samples. After screening, we finally got 2170 samples.

\subsection{Variable definition}

Before adopting the Euler investment equation model, it is necessary to select specific indicators from the financial data of enterprises as the proxy variables of the variables in the model, as showed in Table I.

TABLE I.

VARIABLE PROPERTIES

\begin{tabular}{|c|c|c|}
\hline $\begin{array}{l}\text { Varia } \\
\text { ble }\end{array}$ & Definition & Proxy Variables \\
\hline$I_{i, t}$ & Investment & $\begin{array}{l}\text { Cash paid by enterprises to purchase } \\
\text { fixed assets, intangible assets, and } \\
\text { other long-term assets }\end{array}$ \\
\hline$K_{i, t}$ & Capital & Total assets of the enterprise \\
\hline$Y_{i, t}$ & Income & Business income of the enterprise \\
\hline$C F_{i, t}$ & Cash flow & $\begin{array}{l}\text { Net cash flow from operating } \\
\text { activities }\end{array}$ \\
\hline
\end{tabular}

In the model, ${ }^{I_{i, t}}$ is the investment in the enterprise, which has three measurement methods. The first is using the change value of the net value of fixed assets; the second is using the change value of fixed assets plus depreciation costs; the third is using the indicator of "cash paid for fixed assets investment" in the cash flow statement. The first two methods can not accurately calculate the actual investment amount of the enterprise, so we use the third method. $K_{i, t}$ is the capital of the enterprise. We use the total assets of the enterprise as its proxy variable. $Y_{i, t}$ is the total income of the enterprise, and the operating income of the enterprise is used as its proxy variable, $C F_{i, t}$ is the cash flow, mainly using the net cash flow from operating activities as its proxy variable $^{[5]}$.

\section{An Empirical Analysis of Financing Constraint Model}

\subsection{Statistical description of variables}

Investment, main business income, and cash flow is the main financial indicators of enterprises. To increase the comparability of indicators among different enterprises, we divide these three variables by standardization and then get the descriptive statistics of the main financial variables of enterprises in Table II.

\section{TABLE II. DESCRIPTION OF MAIN FINANCIAL VARIABLES}

\begin{tabular}{|c|l|l|l|l|l|l|l|}
\hline \multirow{2}{*}{ Variables } & \multicolumn{2}{|l|}{ Mean } & Min & Max & S.D & $\begin{array}{l}\text { Varia } \\
\text { nce }\end{array}$ \\
\cline { 2 - 6 } & Statistic & S.E & & & & \\
\hline$\left(\frac{I}{K}\right)_{\mathrm{i}, \mathrm{t}}$ & 0.0516 & 0.0011 & & 0.000004 & 0.4643 & 0.0492 & 0.002 \\
\hline$\left(\frac{Y}{K}\right)_{i, t}$ & 0.6606 & 0.0113 & & 0.0103 & 11.2744 & 0.5241 & 0.275 \\
\hline$\left(\frac{C F}{K}\right)_{i, t}$ & 0.0511 & 0.0016 & & -0.4915 & 0.4074 & 0.0736 & 0.005 \\
\hline
\end{tabular}

The average investment expenditure of the company is 0.0516 , and the standard deviation is 0.0492 , which shows that the investment amount of most enterprises is concentrated around 0.05 . The standard deviation of the main business income of the enterprise reaches 0.5241 , which indicates that the sample data is highly volatile and distributed. There is a large difference in the main business income between enterprises, which will have a great impact on the investment in the enterprise. The mean value of net operating cash flow is 0.511 , but the difference between the maximum value and the minimum value is large, which shows the financial situation of different enterprises is also diverse, and the growth of enterprises is significantly different.

\subsection{Empirical results}

To make a comprehensive analysis of the financing constraints faced by private enterprises, this paper constructs four models I-IV respectively, which correspond to the financing constraints of the whole sample, private enterprises, traditional industries of private enterprises and strategic emerging industries of private enterprises. Table III lists the regression results of the model. 
The F-values of the four models are significant at the significance level of $1 \%$, rejecting the hypothesis that the regression coefficients are all 0 . The adjusted R-squared is close to 0.5 . The main reason is that many factors are affecting the investment decision-making of enterprises, but Euler's investment equation model focuses on analyzing the sensitivity of investment decision-making to cash flow, so the goodness-of-fit is relatively low. Generally speaking, the R-squared of this model is in an acceptable range in the empirical analysis of the Euler investment equation model.

TABLE III. EMPIRICAL MODEL REGRESSION RESULTS OF FINANCING CONSTRAINT MODEL

\begin{tabular}{|l|c|c|c|c|}
\hline Variable & Model I & Model II & Model III & Model IV \\
\hline $\mathrm{C}$ & $\begin{array}{c}0.008^{* * *} \\
(4.450)\end{array}$ & $\begin{array}{c}0.010^{* * *} \\
(3.789)\end{array}$ & $\begin{array}{c}0.010^{* * *} \\
(3.294)\end{array}$ & $\begin{array}{c}0.014^{* * *} \\
(2.571)\end{array}$ \\
\hline$\left(\frac{I}{K}\right)_{\mathrm{i}, \mathrm{t}-1}$ & $\begin{array}{c}1.027 * * * \\
(23.983)\end{array}$ & $\begin{array}{c}1.032^{* * *} \\
(16.985\end{array}$ & $\begin{array}{c}1.006^{* * *} \\
(13.886\end{array}$ & $\begin{array}{c}1.077^{* * *} \\
(9.082)\end{array}$ \\
\hline$\left(\frac{Y}{K}\right)_{\mathrm{i}, \mathrm{t}-1}$ & $\begin{array}{c}-1.738^{* * *} \\
(-8.204)\end{array}$ & $\begin{array}{c}-1.756^{* * *} \\
(-6.063)\end{array}$ & $\begin{array}{c}-1.221^{* * *} \\
(-\end{array}$ & $\begin{array}{c}-2.510^{* * *} \\
(-\end{array}$ \\
\hline$\left(\frac{I}{K}\right)^{2}{ }_{\mathrm{i}, \mathrm{t}-1}$ & $\begin{array}{c}0.000 \\
(0.130)\end{array}$ & $\begin{array}{c}0.001 \\
(0.580)\end{array}$ & $\begin{array}{c}0.002 \\
(1.103)\end{array}$ & $\begin{array}{c}-0.012^{*} \\
(- \\
1.726)\end{array}$ \\
\hline$\left(\frac{C F}{K}\right)_{\mathrm{i}, \mathrm{t}-1}$ & $\begin{array}{c}0.045^{* * *} \\
(4.184)\end{array}$ & $\begin{array}{c}0.050^{* * *} \\
(3.126)\end{array}$ & $\begin{array}{c}0.044^{* *} \\
(2.447)\end{array}$ & $\begin{array}{c}0.091^{* * *} \\
(2.774)\end{array}$ \\
\hline $\mathrm{N}$ & 2167 & 1293 & 825 & 409 \\
\hline Adj.R ${ }^{2}$ & 0.460 & 0.423 & 0.493 & 0.423 \\
\hline $\mathrm{F}$ & $463.085^{* * *}$ & $\begin{array}{l}238.103 * * \\
*\end{array}$ & $201.637 * *$ & $50.992^{* * *}$ \\
\hline
\end{tabular}

The coefficients $\beta_{1}, \beta_{2}, \beta_{3}, \beta_{4}$ respectively reflect the sensitivity of enterprises' investment behavior in each sample to each variable.

Model I is a regression analysis of the whole sample to test the overall financing constraints of China's manufacturing industry. The regression results show $\beta_{1}>1, \beta_{2}<-1, \beta_{3} \geq 0$, and the regression coefficient of $\left(\frac{C F}{K}\right)_{i, t-1}$ is 0.045 , which is significant at the level of $1 \%$. This means that the capital investment of enterprises is positively related to cash flow, and the Chinese manufacturing industry generally faces external financing constraints.

Model II is a regression analysis of private enterprises to test the financing constraints of private enterprises. The regression results show $\beta_{1}>1, \beta_{2}<-1, \beta_{3} \geq 0$, and the sensitivity of enterprise investment cash flow in model II is 0.05 , which is higher than the estimated value of model I. This shows that compared with state-owned enterprises, the investment of the private enterprises is more sensitive to the internal cash flow, and the private enterprises faced with more serious financing constraints. The difference like enterprise ownership has a significant impact on the degree of financing constraints. Private enterprises face credit discrimination.

Model III and Model IV respectively conduct regression analysis on private traditional enterprises and private strategic emerging enterprises to test the financing constraints of private enterprises. The regression results show that $\beta_{1}>1, \beta_{2}<-1, \beta_{3} \geq 0$, and the investment cash flow sensitivity of private emerging industries in model IV is 0.091 , which is far higher than the other three models. This means that there are significant differences in the financing constraints faced by different industries of private enterprises. Compared with traditional industries, the financing constraints faced by private strategic emerging industries are more serious, and the allocation of financial resources to strategic emerging industries is insufficient.

\subsection{Analysis of empirical results}

The empirical analysis of the model shows that Chinese enterprises generally face financing constraints, but compared with state-owned enterprises, the financing constraints of private enterprises are greater. Among them, the financing constraint of private strategic emerging industries is the most serious. This problem is mainly caused by multiple factors such as the business operation, financial system, and financial environment.

1) The development of the financing system is relatively backward: In the past 40 years of reform and opening-up, China's financial system has been reformed many times and achieved great achievements. It initially establishes a multi-level capital market and financial system. However, it is still an indisputable fact that China's financial system is not perfect. The single external financing channel has become a gap between the enterprise and the financial system. At present, stateowned commercial banks still play a leading role in China's financial system, and bank loans are still the main channel of domestic social financing. In recent years, although the capital market has developed rapidly, there are still many problems, which directly leads to the lack of external financing, the shortage of long-term funds, and the lack of efficiency in the allocation of financial resources. The proportion of direct financing is relatively small, and the efficiency of the medium function of the financing system is low, which has become a "roadblock" for enterprise financing.

2) Many private enterprises are small in scale and have different qualifications: The core of finance is credit. Private enterprises account for a relatively high proportion of the total economic volume, but compared with large-scale state-owned enterprises, their scale is small, and their qualifications are mixed. Many private business owners are relatively conservative, and the tendency of seeking survival, stability and short-term profit is common. The development of enterprises often lacks a perfect independent innovation mechanism and long-term strategy, and the phenomenon of "rapid rise and rapid fall" still exists. Besides, many private enterprises' financial information is not transparent. Banks are difficult to grasp the true and accurate information, or the cost of information collection and 
processing is too high, which directly affects the enthusiasm of credit granting. Financial institutions are still reluctant to lend to private enterprises, and the phenomenon of "discrimination" still exists.

3) The financial infrastructure construction is not perfect: Perfect financial infrastructure, such as a credit guarantee system, financial credit system, financing support policies, can alleviate the information asymmetry between banks and enterprises, provide convenience for financing, and solve the financing problems of private enterprises. However, after years of development, there are still some shortcomings in China's financial infrastructure construction. Strategic emerging industries in private enterprises are most affected by these problems. Compared with the traditional industries, the private strategic emerging enterprises are mostly small and medium-sized enterprises in the initial stage, whose development investment can not be satisfied by the self accumulation of enterprises, and they are very dependent on external financing. However, the risk of $R \& D$, industrialization and marketization of these enterprises is very high. They also have a relatively small proportion of fixed assets and are difficult to value when financing. Therefore, for the consideration of adverse selection and moral hazard, the best investment decision of external investors is to avoid strategic emerging industries and turn to traditional industries, which makes the most serious problem of financing constraints in the development of strategic emerging industries.

\section{Measures to alleviate the financing constraints of private enterprises}

\subsection{Deepen the structural reform of the financial supply-side and increase the proportion of direct financing}

At present, the financing constraint of Chinese enterprises is not only a total amount problem of capital shortage but also a structural problem. The supply and demand dislocation, term mismatch and structural mismatch is common. Therefore, to meet the diversified financing needs of private enterprises, we need to make efforts by the financial supply side, promote structural reform, to optimize the financing function of the financial system and serve the development of the real economy. On the one hand, we should give full play to the role of the main channel of bank credit and increase the credit allocation of private enterprises. On the other hand, we should improve the capital market and increase the proportion of direct financing of private enterprises. The capital market is an important channel for enterprises to obtain long-term capital. To solve the problem of structural imbalance, we must rely on the multi-level capital market and give full play to the direct financing function of the stock market and bond market, moderately accelerate the speed of private enterprises' listing financing, expand the scale of private enterprises' direct financing, and help ease the financial difficulties of enterprises.

\subsection{Set up the consciousness of high-quality development and promote the transformation and upgrading of private enterprises}

The financing constraints of private enterprises are caused by both internal and external factors. To solve this dilemma, we must solve the problems of the short life cycle, poor profitability and low credit rating of private enterprises. The root of these problems lies in the lack of innovation ability, lack of strategic planning and weak awareness of credit. Therefore, we should help enterprises establish a high-quality development awareness and promote the transformation and upgrading of enterprises. Many private enterprises, because of their short development time and insufficient knowledge of industry information, are difficult to accurately grasp the market demand and competition situation, and often step into the development minefields such as over financing and term mismatch. The government can set up a platform to actively guide private enterprises to improve their understanding of business risks, to avoid blind diversification and excessive expansion.

\subsection{Improve financial infrastructures and create a favorable financing environment}

To solve the financing dilemma of private strategic emerging enterprises and stimulate the vitality of private enterprises, we need to improve the construction of financial infrastructure, create a better financial ecology, achieve a high degree of agreement between financing supply and private enterprise capital demand, and make private enterprises secure development. On the one hand, we should build a multi-level credit guarantee system to increase the credit of indirect financing. Financial resources are naturally profit-seeking and risk-averse. Compared with large-scale state-owned enterprises, the investment risk of private strategic emerging enterprises is relatively high. It is necessary to build a "three in one" credit guarantee system which combines policy guarantee, commercial guarantee, and mutual guarantee, to disperse investment risks and increase credit for private enterprises. On the other hand, it is necessary to improve the credit system of private enterprises, build a credit information sharing mechanism, open up information exchange channels, and promote the efficient allocation of credit resources.

\section{Conclusion}

To analyze the financing difficulty and high cost of private enterprises in China, this paper uses the financial data of A-share listed enterprises to construct four sets of Euler investment equation models.

The empirical analysis of the model shows that Chinese enterprises generally face financing constraints. 
However, compared with state-owned enterprises, the financing constraints of private enterprises are greater. Among them, the financing constraint of private strategic emerging industries is the most serious. To solve the financing dilemma of private enterprises, we need to deepen the structural reform of the financial supply-side, promote the transformation and upgrading of private enterprises, improve financial infrastructure and create a favorable financing environment.

\section{References}

1. F.Modigliani, M. Miller. "The cost of capital, corporation finance, and the theory of investment," American Economic Review, 1958, pp. 639-655.

2. S.R. Fazzari, D. G.Hubbard, B. C.Petersen. "Financing constraints and corporate investment,"
Brookings Papers on Economic Activity, 1988, PP. 141-195.

3. Y. Yang, L. Wang, "The effect of financing constraints on OFDI of China's enterprise," Education and Social Sciences, 2017, PP. 639-644.

4. M. Song, H. Ai, X.Li. "Political connections, financing constraints, and the optimization of innovation efficiency among China's private enterprises," Technological Forecasting \& Social Change, 2015.

5. W. Zuguang, W. Xinyue. "Research on the paths of financial marketization promoting private agriculture enterprise development_empirical evidence from exempted listed agriculture companies," Advances in Economics,business and Management Research, 2017, pp. 94-98. 